\title{
SALSA - a Sectional Aerosol module for Large Scale Applications
}

\author{
H. Kokkola ${ }^{1}$, H. Korhonen ${ }^{2,3}$, K. E. J. Lehtinen ${ }^{1,3}$, R. Makkonen $^{4}$, A. Asmi ${ }^{4}$, S. Järvenoja ${ }^{2, \dagger}$, T. Anttila ${ }^{2}$, \\ A.-I. Partanen ${ }^{1}$, M. Kulmala ${ }^{4}$, H. Järvinen ${ }^{2}$, A. Laaksonen ${ }^{2,3}$, and V.-M. Kerminen ${ }^{2}$ \\ ${ }^{1}$ Finnish Meteorological Institute, Kuopio Unit, P.O.Box 1627, FI-70211 Kuopio, Finland \\ ${ }^{2}$ Finnish Meteorological Institute, P.O.Box 503, FI-00101 Helsinki, Finland \\ ${ }^{3}$ Department of Physics, University of Kuopio, P.O.Box 1672, FI-70211 Kuopio, Finland \\ ${ }^{4}$ Department of Physical Sciences, P.O.Box 64, FI-00014 University of Helsinki, Finland \\ †Deceased 16 October 2007
}

Received: 1 November 2007 - Published in Atmos. Chem. Phys. Discuss.: 10 December 2007

Revised: 7 April 2008 - Accepted: 10 April 2008 - Published: 8 May 2008

\begin{abstract}
The sectional aerosol module SALSA is introduced. The model has been designed to be implemented in large scale climate models, which require both accuracy and computational efficiency. We have used multiple methods to reduce the computational burden of different aerosol processes to optimize the model performance without losing physical features relevant to problematics of climate importance. The optimizations include limiting the chemical compounds and physical processes available in different size sections of aerosol particles; division of the size distribution into size sections using size sections of variable width depending on the sensitivity of microphysical processing to the particles sizes; the total amount of size sections to describe the size distribution is kept to the minimum; furthermore, only the relevant microphysical processes affecting each size section are calculated. The ability of the module to describe different microphysical processes was evaluated against explicit microphysical models and several microphysical models used in air quality models. The results from the current module show good consistency when compared to more explicit models. Also, the module was used to simulate a new particle formation event typical in highly polluted conditions with comparable results to more explicit model setup.
\end{abstract}

\section{Introduction}

Aerosols are currently an inherent part of many types of large-scale atmospheric models, including regional and

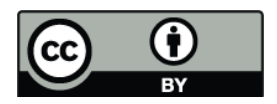

Correspondence to: $\mathrm{H}$. Kokkola (harri.kokkola@fmi.fi) global climate models, air quality models and chemical transport models. There are two things that need to be kept in mind when designing the description of aerosols in these models. First, the climatic and other effects of atmospheric aerosols have been demonstrated to be sensitive to aerosol size distribution, size-resolved chemical composition and the mixing state of the particles (Myhre et al., 2004; Chen and Penner, 2005). Second, understanding the linkage between the emissions of aerosols or their precursors and various impacts by these aerosols is not possible without consideration of the atmospheric processes that modify the different aerosol properties (Adams and Seinfeld, 2002; Spracklen et al., 2005).

Treating aerosols in a large-scale modeling framework is always a compromise between the detail of description and computational efficiency. One approach in this regard is to approximate the aerosol population as a sum of a small number of log-normal modes. The modal approach has been used in regional air quality models for more than a decade (Binkowski, F. S. and Shankar, 1995; Ackermann et al., 1998; Binkowski and Roselle, 2003), and more recently it has also been applied to various global modeling frameworks (Ghan et al., 2001; Wilson et al., 2001; Stier et al., 2005). The drawback of the modal approach is that many of the processes relevant to indirect climatic aerosol effects such as aerosol formation and growth, cloud processing, and aerosol ageing in terms of its cloud nucleating properties, are difficult to simulate properly. Also, the calculation of the effective radii of the particles can be inaccurate when using modal approach (Weisenstein et al., 2007)

A more general way of treating aerosols in large-scale models is to describe the aerosol size distribution with a limited number of moments (McGraw, 1997). All aerosol

Published by Copernicus Publications on behalf of the European Geosciences Union. 
processes in this approach are tied into the moments and thus getting information about their physical values at any time requires a separate retrieval. The moment approach is computationally very effective but has basically the same drawbacks as the modal approach. Additionally, the modal approach is not intuitive for use, as the modal values themselves are not observed parameters beyond the first few integer values.

In principle, sectional models can be used to avoid the problems associated with modal and moment approaches. However, the calculation of microphysical processes affecting the aerosol size distribution using sectional approach is usually more computationally demanding than modal or moment method approaches. On the other hand, a sectional model can describe different microphysical processes more accurately than modal and moment methods. Because of the computational demands, sectional approaches have often neglected one or more major aerosol types and assumed an internal mixture between the simulated components (Jacobson, 2001; Rodriguez and Dabdub, 2004; Spracklen et al., 2005 , e.g.). Another way of tackling this problem is to apply the sectional approach for some of the aerosol sizes and to treat the rest of the aerosol sizes using either modal or bulk mass based approach (Liao and Seinfeld, 2005; Liu et al., 2005; Reddy et al., 2005). Nevertheless, in the approaches by Liao and Seinfeld (2005) and Reddy et al. (2005) the sectional, modal and bulk aerosol components are completely non-interacting.

There are several ways to improve the efficiency of a sectional aerosol model. Most importantly, the model development should concentrate on the main application of the model (e.g. climate effects in this case) and try to minimize less important processes on different aerosol sizes and compositions. Especially, reduction of number of computational tracers is of major importance, as they affect the model efficiency severely. We have developed a new aerosol model, which tries to approach the simulations of aerosol dynamics from climate effect point of view using a highly flexible sectional model approach, with computational efficiency as a major design criteria.

\section{Model description}

There are several ways by which the computational efficiency of multi-component sectional aerosol models could be improved to make them more suitable for large scale applications. We postulate the major design choices of our improvements:

1. The width of the particle size bins need not be fixed as usually assumed. Instead, lower size resolution could be used in regions influenced less by microphysical processes, or in regions that are less important for the problem under investigation;
2. Since different aerosol types are concentrated over different parts of the particle size spectrum, the set of chemical components included in simulations could vary between different size regions;

3. The relative importance of different microphysical processes varies strongly with particle size. This makes it possible to simplify the treatment of individual aerosol processes, or to neglect them altogether, in some particle sizes.

The model developed in this study is designed to use the simplification mentioned above to minimize the amount of calculations and the variables passed on to the host climate model to maximize the computational efficiency of the model without compromising too much the accuracy of the aerosol model.

Using these basic postulates as our design criteria, we have created a highly flexible modelling framework SALSA. In the following we present the description of the model and the suggested base configuration for climate studies.

2.1 Representing the chemically-resolved aerosol size distribution

In SALSA, the particle size spectrum has been divided into a small number of sub-ranges. The number of size bins, chemical components, externally mixed groups of particles and simulated processes in each of the subranges, as well as the rough locations of the borders between the sub-ranges, have been chosen based on the following criteria:

1. What aerosol sources and sinks are important?

2. What atmospheric processes are relevant?

3. What chemical components need to be included?

4. How the aerosol mixing state should be described?

5. Which aerosol quantities need to be modelled accurately to obtain relevant climate or air quality effects?

After this, the number of size bins, chemical components, externally mixed groups of particles, and simulated processes can be optimized for each sub-range of the distribution.

In selecting the number of sub-ranges and boundaries between them, we started from the fact that the smallest aerosol particles have totally different sources and behavior in the atmosphere as compared with the largest particles. "Middlesized" particles between these two extremes have some characteristics of their own, in addition to which they may have some features similar to either small or large particles. The minimum number of necessary sub-ranges is therefore three, which is also the number chosen for SALSA. Starting from the lower-end of the particle size spectrum, we term these as the sub-range 1, sub-range 2 and sub-range 3 (Fig. 1, and Table 1). 
The degree of external mixing usually increases when going from the smallest particle sizes to sizes affected by primary particulate emissions (e.g. Väkevä et al., 2002; Ferron et al., 2005; Sakurai et al., 2005). As a result, we have chosen to have only one internally-mixed group of particles in the sub-range 1 , whereas in the sub-range 2 we have two externally-mixed groups of particles termed insoluble and soluble particles. Due to the diversity of their sources and slow ageing by microphysical processes, supermicron particles are likely to possess the highest degree of external mixing in the atmosphere. This is reflected in SALSA as having three externally-mixed groups of particles in sub-range 3. More details of these selections are given below.

The smallest particles constituting the sub-range 1 originate entirely from atmospheric nucleation processes. In large-scale models, only so-called "regional" nucleation events producing particles over horizontal scales of tens to hundreds of kilometers can be considered important (Kulmala et al., 2004; Spracklen et al., 2006). Although nucleation mechanisms and participating vapors may vary between different atmospheric compartments, particles formed in each regional nucleation event are expected to be internally well mixed. As a result, particles in sub-range 1 are chemically much simpler than larger particles, making it desirable to extend this sub-range to as large sizes as possible.

The two main factors that push the boundary between subranges 1 and 2 down are that we do not want sub-range 1 to take part in cloud processing or to contain significant amounts of primary particles, especially soot. The smallest particles able to activate into cloud droplets have been observed to be in the diameter range 50-100 nm (e.g. Henning et al., 2002; Komppula et al., 2005; Mertes et al., 2005), so cloud processing is not a very strong constraint. The number size distribution of combustion-derived soot particles vary greatly but peak typically between about 50 and $200 \mathrm{~nm}$ (e.g. Chang et al., 2004; Iinuma et al., 2007). Black carbon (BC) associated with soot can be found down to particle sizes of 20-30 nm but its fractional contribution to particle mass seems to be usually small in diameter range $<50 \mathrm{~nm}$ (Wehner et al., 2004; Jaffrezo et al., 2005; Iinuma et al., 2007). As a compromise between these constraints, we place initially the limit between sub-ranges 1 and 2 at around $50 \mathrm{~nm}$.

The atmospheric coarse particle size range, termed here sub-range 3, contains a versatile set of usually externallymixed aerosol types. The main particle types in this size range are sea-salt particles, desert dust, biological debris and industrial dust (e.g. Seinfeld and Pandis, 1998). At minimum, three externally-mixed particle types should be treated in sub-range 3. The first of these are fully-soluble sea-salt particles whose "wet" size and thereby scattering properties depend greatly on the ambient relative humidity (e.g. Tang, 1997). Insoluble particles, such as freshly-emitted desert dust particles, do not act as cloud condensation nuclei (CCN) but may instead act as cloud nuclei (e.g. Cantrell and Heymsfield, 2005). Atmospheric ageing processes turn insoluble particles gradually into soluble ones, i.e. into particles able to act as CCN. Contrary to sea-salt particles, the "wet" size of aged insoluble particles responds very weakly to changes in the ambient relative humidity, which makes them optically very different from sea-salt particles.

Another specific feature for sub-range 3 is that various microphysical processes, while modifying the particle number concentration and chemical composition, change very little the "dry" size of individual particles. As a result, we will assume in SALSA that the "dry" size of individual particles remains fixed in sub-range 3. This helps the treatment of these chemically complex particles in SALSA but creates a constraint that the limit between sub-ranges 2 and 3 should be above $500 \mathrm{~nm}$. On the other hand, from computational reasons it would be highly desirable that we could exclude desert dust from sub-range 2. The number size distributions of emitted desert dust particles peak typically slightly below $1000 \mathrm{~nm}$, whereas $>80-90 \%$ of the dust mass is usually found in the size range $>1000 \mathrm{~nm}$ (Alfaro and Gomes, 2001; Grini and Zender, 2004). By considering these things together, we place the limit initially between sub-ranges 2 and 3 at around $700-800 \mathrm{~nm}$.

There are several possibilities on how to optimize the exact limits between sub-ranges 1,2 and 3. Here this optimization was made by calculating the number concentration of activated cloud droplets (CDNC) in vertical updrafts using both SALSA (see Sect. 2.6 for the details of activation treatment in SALSA) and high-resolution cloud parcel model with 300 size bins. Updraft velocities were varied in the range 0.1$1 \mathrm{~m} / \mathrm{s}$ and simulations were repeated for three different particle number size distributions representing urban, rural and marine aerosols (Jaenicke, 1993). For simplicity, only sulfate and black carbon (BC) were taken into account in this optimization. The insoluble particles were assumed to consist of only $\mathrm{BC}$ and the soluble particles were a mixture of sulfate and $\mathrm{BC}$. The number fraction of insoluble particles was varied between $0-0.5$ and the volume fraction of $\mathrm{BC}$ in soluble bins was also varied between $0-0.5$.

In the optimization procedure, it was found out that the composition has very little effect on the optimal limits between the subranges. For the compositions used, the optimal limits were within $2 \mathrm{~nm}$ for all the cases. On the other hand, the shape of the number size distribution has a significant effect on the optimal limits. The higher the total number concentration, the more sensitive the number of activated droplets is to the limits between the subranges. For example, for the urban size distribution, a $10 \mathrm{~nm}$ change in the limit between subranges 1 and 2 changed the number of activated droplets approximately 50 -fold for updraft velocities higher than $0.5 \mathrm{~m} / \mathrm{s}$. For the rural case, a $10 \mathrm{~nm}$ change in the limit between subranges 1 and 2 amounted to a maximum of $20 \%$ change and for the marine case, to a maximum of $8 \%$ change.

Since the direct effect of aerosols can effect climate forcing also in cloud covered regions (Boucher and Anderson, 1995), the effects of the subrange limits on the radiation were 


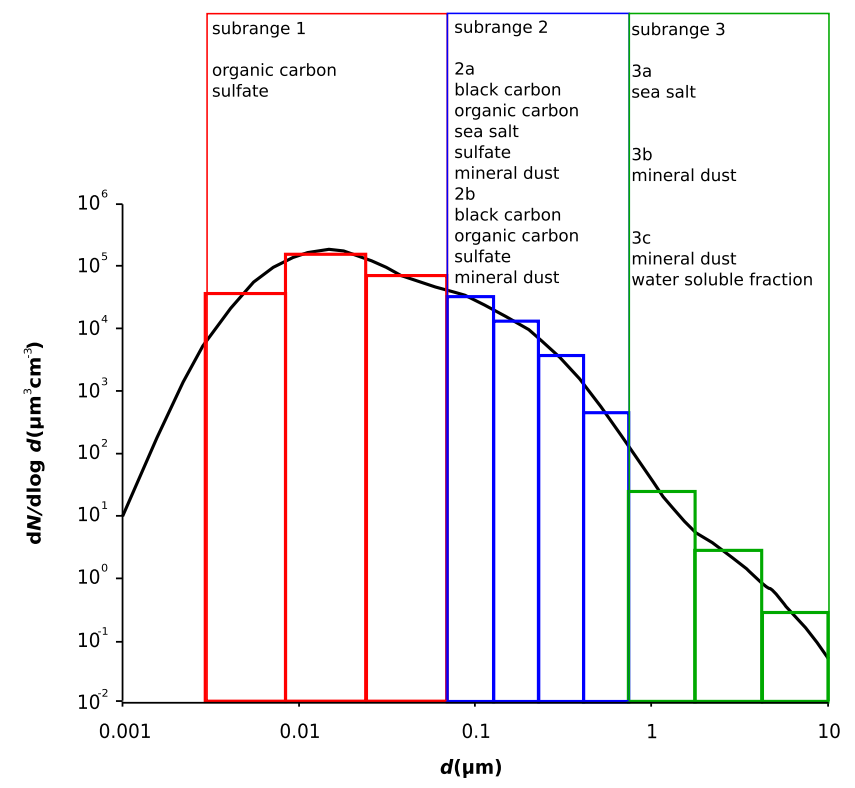

Fig. 1. Schematic of the division of size distribution into subranges and sections in the aerosol model SALSA.

Table 1. Low and high diameter limits for subranges

\begin{tabular}{lccc}
\hline Subrange & 1 & 2 & 3 \\
\hline low limit & $3 \mathrm{~nm}$ & $50 \mathrm{~nm}$ & $730 \mathrm{~nm}$ \\
high limit & $50 \mathrm{~nm}$ & $730 \mathrm{~nm}$ & $10 \mu \mathrm{m}$ \\
\hline
\end{tabular}

also tested by calculating the extinction coefficient of the particle population according to Bohren and Huffman (1983). The extinction coefficients were calculated for number size distributions representing urban, rural and marine aerosols (Jaenicke, 1993) assuming that the insoluble size bins consist completely of black carbon and varying the composition in soluble size bins. The particle number concentrations were set to be equal for parallel insoluble and soluble size bins to get the most amplified effect of the values of the limits on the extinction coefficient. The extinction coefficient was then calculated for the given size distribution and composition varying the relative humidity between $40 \%$ and $100 \%$.

According to these tests, the CDNC activation is much more sensitive to subrange limits than the radiative effects of the aerosols. Furthermore, the sensitivity of the radiative properties on the subrange limits was found to be highest for the urban case. For example, for the urban size distribution, a $10 \mathrm{~nm}$ change in the limit between subranges 1 and 2 leads in maximum to a $20 \%$ change in the extinction coefficient.

According to the optimization procedure for the subrange limits, the limit between subranges 1 and 2 was chosen to be
Table 2. Parameters for the size distributions used in coagulation and condensation tests, taken from Zhang et al. (1999). Subscripts $n, a$, and $c$ refer to nuclei, accumulation, and coarse modes, respectively.

\begin{tabular}{lccc}
\hline Parameter & Clear & Hazy & Urban \\
\hline Mean diameter $(\mu \mathrm{m})$ & & & \\
$d_{n}$ & 0.03 & 0.044 & 0.038 \\
$d_{a}$ & 0.2 & 0.24 & 0.32 \\
$d_{c}$ & 6.0 & 6.0 & 5.7 \\
Standard deviation & & & \\
$\sigma_{n}$ & 1.8 & 1.2 & 1.8 \\
$\sigma_{a}$ & 1.6 & 1.8 & 2.16 \\
$\sigma_{c}$ & 2.2 & 2.2 & 2.21 \\
Total volume $\left(\mu \mathrm{m}^{3} \mathrm{~cm}^{-3}\right)$ & & & \\
$V_{n}$ & 0.03 & 0.09 & 0.63 \\
$V_{a}$ & 1.0 & 5.8 & 38.4 \\
$V_{c}$ & 5.0 & 25.9 & 30.8 \\
\hline
\end{tabular}

$50 \mathrm{~nm}$ and the limit between subranges 2 and 3 was chosen to be $730 \mathrm{~nm}$.

A schematic picture on the representation of the particle size distribution and chemical composition in SALSA is given in Fig. 1 and the summary of the subrange limits is given in Table 1 . The total number of size bins ( 3 in the subrange $1,2 \times 4$ in the sub-range 2 and $3 \times 3$ in the sub-range 3 ) is our default model set up designed for large-scale modeling purposes. This number is adjustable and can be chosen differently for different types of simulations and/or model configurations. The size bins within subranges have a constant volume ratio between adjacent size bins. A more detailed summary of the three sub-ranges is given below:

Subrange 1:

Particles smaller than $50 \mathrm{~nm}$ in diameter are assumed to originate mainly from atmospheric nucleation, even though primary organic particles can be included as well. Active processes in this sub-range are condensation growth, coagulation and dry deposition, whereas cloud processing can be excluded. In all size sections of this regime, particles are assumed to be internally mixed and contain only sulfate and organic matter.

Subrange 2:

Particles having diameters between 50 and $730 \mathrm{~nm}$ are assumed to originate either from primary emission or to evolve from the sub-range 1 by active growth processes (condensation and coagulation). The main chemical components for this subrange are sulfate, primary organics, black carbon, low-volatile secondary organics, mineral dust and sea salt. In the aerosol model, the subrange is divided into four size sections. Since in the atmosphere there is some degree of external mixing for particles of these sizes, and especially as the composition of these external mixtures can play a significant 
role in cloud activation and light scattering, the model assumes two externally-mixed parallel size bins for each size section ( $2 \mathrm{a}$ and $2 \mathrm{~b}$; see Fig 1 ). The sizes of particles in subrange 2 are fairly insensitive to processing by coagulation and dry deposition. The particles in this subrange are important in cloud activation as they are the dominant source of cloud droplets. Also, wet deposition is a significant sink for these particles. For these reasons, subrange is described using a higher resolution of size sections.

\section{Subrange 3:}

This sub-range $(>730 \mathrm{~nm}$ ) contains primary particles from mainly natural sources. Three externally-mixed particle types (sea salt, insoluble dust, soluble dust) are assumed in SALSA. Water soluble compounds other than sea-salt (such as sulfate, and biogenic organics) are treated in subrange 3 as one compound. This water soluble fraction is included as part of the insoluble dust group.

Particles in this sub-range are affected by both dry and wet deposition, in addition to which these particles are allowed to scavenge smaller particles by coagulation. The "dry" size of the individual particles in this sub-range is assumed to be unaffected by simulated processes. Three size sections, each containing three parallel size bins for externally-mixed particle types, are chosen for this sub-range (referred to as $3 \mathrm{a}, 3 \mathrm{~b}$, and 3c; see Fig. 1).

\subsection{Treatment of microphysical processes}

The microphysical processes included in the model are nucleation, coagulation, condensation, cloud activation, sulfate production and hydration. The processes are calculated for each fixed time step independently, except for nucleation and condensation which are calculated simultaneously to represent the competition between these processes more accurately. The redistribution of particles which grow or shrink out of the boundaries of their initial size bin are redistributed to the appropriate new size bins at the end of each time step, when all microphysical processes have been already taken into account.

For sparse size bins, the moving center scheme has proven to be an efficient way to describe the time dependent development of particle size distribution (Jacobson, 2005) and this method is also used in the current aerosol model for particles in the subranges 1 and 2. Since aerosol dynamics do not affect particles larger than $730 \mathrm{~nm}$ significantly, size bins in subrange 3 are treated in a fixed sectional grid to decrease the calculation time and the number of tracers in the model.

The division between insoluble and soluble bins in subrange 2 requires further explanation. As insoluble particles grow in subrange 2 they collect soluble compounds from condensation and thus their water uptake increases. We have selected the particles that are able to form cloud droplets in $0.5 \%$ supersaturation to be "soluble", rest "insoluble". This way we have tried to get more climatologically relevant choice of solubilitity, which can provide the most appropriate measure of particle ability to act as a $\mathrm{CCN}$.

\subsection{Nucleation and condensation}

Nucleation is taken into account by calculating the rate of formation of $3 \mathrm{~nm}$ sized particles resulting from nucleation processes. This is calculated using the expression for the parameterized formation rate of detectable $3 \mathrm{~nm}$ particles given by Kerminen and Kulmala (2002). The parameterization calculates the formation rate $J_{\text {app }}$ of $3 \mathrm{~nm}$ particles using the "real" nucleation rate $J(t)$ using equation

$J_{\text {app }}\left(d_{\mathrm{p}}, t^{\prime}\right)=J(t) \exp \left(\frac{\eta}{d_{\mathrm{p}}}-\frac{\eta}{d_{\text {nuc, ini }}}\right)$,

where $t^{\prime}-t=\left(d_{\mathrm{p}}-d_{\text {nuc,ini }}\right) / \mathrm{GR}$ is the time difference between formation of nuclei of critical diameter $d_{\text {nuc,ini }}$ and their growth to diameter $d_{\mathrm{p}}$, GR $\left(\mathrm{m} \mathrm{s}^{-1}\right)$ denoting the nuclei growth rate calculated according to Kerminen and Kulmala (2002), where the details of calculating parameters in Eq. (1) are given. The reason for this shift in size-space is the choice of minimum size of the particles in SALSA.

The "real" nucleation rate in equation (1) can be calculated in the default model setup using description for binary nucleation (Vehkamäki et al., 2002), ternary nucleation (Napari et al., 2002a,b), kinetic nucleation (Sihto et al., 2006; Riipinen et al., 2007), or activation type nucleation (Kulmala et al., 2006; Riipinen et al., 2007). However, other methods of nucleation mechanisms can be used, if the host model together with SALSA can provide the necessary inputs for parameterizations.

Mass transfer of gas molecules to particles is calculated using the Analytical Predictor of Condensation scheme with a saturation vapor pressure set to zero (Jacobson, 1997) using the expression for the collision rate by Lehtinen et al. (2004). Nucleation is solved concurrently with condensation using the scheme by Jacobson (2002).

\subsection{Hydration}

The equilibrium sizes of particles in different size bins $j$ are calculated using the ZSR method (Stokes and Robinson, 1996). The water content $c_{w}\left(\mathrm{~kg} \mathrm{~m}^{-3}\right)$ in particles is given by equation

$c_{w}=\sum_{j=1}^{n} \frac{c_{j}}{m_{j, a}}$.

In the equation, $c_{j}$ is the molar concentration of species $j$, and $m_{j, a}$ is the molality of solute species alone in the solution. Summation in (2) is done over all solute species in each size bin. To decrease the amount of calculation, hydration is not calculated for insoluble size bins in subranges $3 \mathrm{~b}$ and $3 \mathrm{c}$. 
The binary molalities for inorganic salts are calculated using parameterizations given by Jacobson (2005). For organic compounds, binary molality is calculated using equation

$m_{j, a}=1 /\left(a_{w} v_{w}\right)-1 / v_{w}$,

where $v_{w}$ is the molar volume of water and $a_{w}$ is the water activity. Equation (3) assumes ideal behavior for the organics.

\subsection{Coagulation}

In a typical large scale aerosol code, coagulation calculations are one of the most computationally expensive among the different microphysical processes. To decrease the calculation time, coagulation is not calculated for all collision pairs.

The collision pairs are chosen as follows:

- The particles in subrange 1 are assumed to collide with all particles in subranges 2 and 3. Additionally, particles in subrange 1 are assumed to collide with particles in larger size bins in subrange 1 .

- The particles in subrange $2 \mathrm{a}$ are assumed to collide with all particles in subrange 3 and particles in larger size bins in subranges $2 \mathrm{a}$ and $2 \mathrm{~b}$.

- The particles in subrange $2 b$ are assumed to collide with all particles in subrange 3 and particles in larger size bins in subranges $2 \mathrm{a}$ and $2 \mathrm{~b}$. Additionally, the particles in subrange $2 \mathrm{~b}$ are assumed to collide with particles in the parallel size bin in subrange 2a.

- The collisions between the particles in subrange 3 are not taken into account due to small coagulation coefficient between particles larger than $730 \mathrm{~nm}$ (see e.g., Seinfeld and Pandis, 1998).

The changes in particle number and volume concentrations due to coagulation are then calculated using the semiimplicit coagulation scheme which requires no iteration (Jacobson, 1994).

\subsection{Cloud droplet activation}

The number of activating cloud droplets is calculated using parameterization by Abdul-Razzak et al. (1998); AbdulRazzak and Ghan (2002). Coarse sectional resolution (i.e. wide size bins) can cause problems with cloud activation when each bin covers a fairly wide range of critical supersaturations. One possibility around this problem is to activate only a fraction of the particles in the critical size bin. The easiest way to do this is to assume a number concentration profile inside the critical size bin. This can be done in several ways. Korhonen et al. (2005) have presented a method to describe the number concentration using linear dependency between the centers of two adjacent size bins. In this model, the method by Korhonen et al. (2005) was further improved by assuming the number concentration dependence between two bins to be of 2 nd order polynomial form. Figure 2 illustrates the calculated number of activated cloud droplets (CDNC) for urban conditions using three different approaches to describe the size distribution in a bin. The results are compared with a high resolution solution obtained using 300 size bins in size space (thick black curve). The first approach was to assume constant number concentration within one bin (dash-dot curve). Second, the method by Korhonen et al. (2005) was used (dashed curve). Third, a modified method of Korhonen et al. (2005) was used: the number concentration inside the bin was described with a 2 nd order polynomial function dependent on the particle concentration in the surrounding size bins.

From Fig. 2 it can be seen that the accuracy in the CDNC is significantly increased when a 2 nd order polynomial function is used to describe the number size distribution within a size bin.

\subsection{Sulfate production in cloud droplets}

SALSA calculates the sulfate production calculating the oxidation of $\mathrm{SO}_{2}$ by $\mathrm{H}_{2} \mathrm{O}_{2}$ and $\mathrm{O}_{3}$ in cloud droplets. The aqueous phase concentration of $\mathrm{SO}_{2}$ is calculated according to Henry's law, accounting for dissolution effects (see e.g. Seinfeld and Pandis, 1998). The liquid water available for liquid phase chemistry is calculated from the liquid water content dividing the liquid water equally among activating cloud droplets.

\subsection{Other processes}

The aerosol model SALSA itself calculates only processes described above. Other processes have to calculated in the host large scale model, which SALSA is coupled with. The treatment of other processes, such as particle emissions, dry and wet deposition, and radiative effects of the aerosols are dependent on the host model.

\section{Model evaluation}

\subsection{Coagulation and condensation}

The performance of the aerosol model was tested by calculating different microphysical processes and comparing the results against previous aerosol models used in large scale models. Coagulation and condensation were tested comparing the model results and a model comparison for air quality models by Zhang et al. (1999). This comparison also included accurate numerical solutions for condensation and coagulation that have been calculated using an explicit microphysical models CONFEMM and COAGUL for condensation and coagulation, respectively. The simulations were made for different time step lengths using default values for 


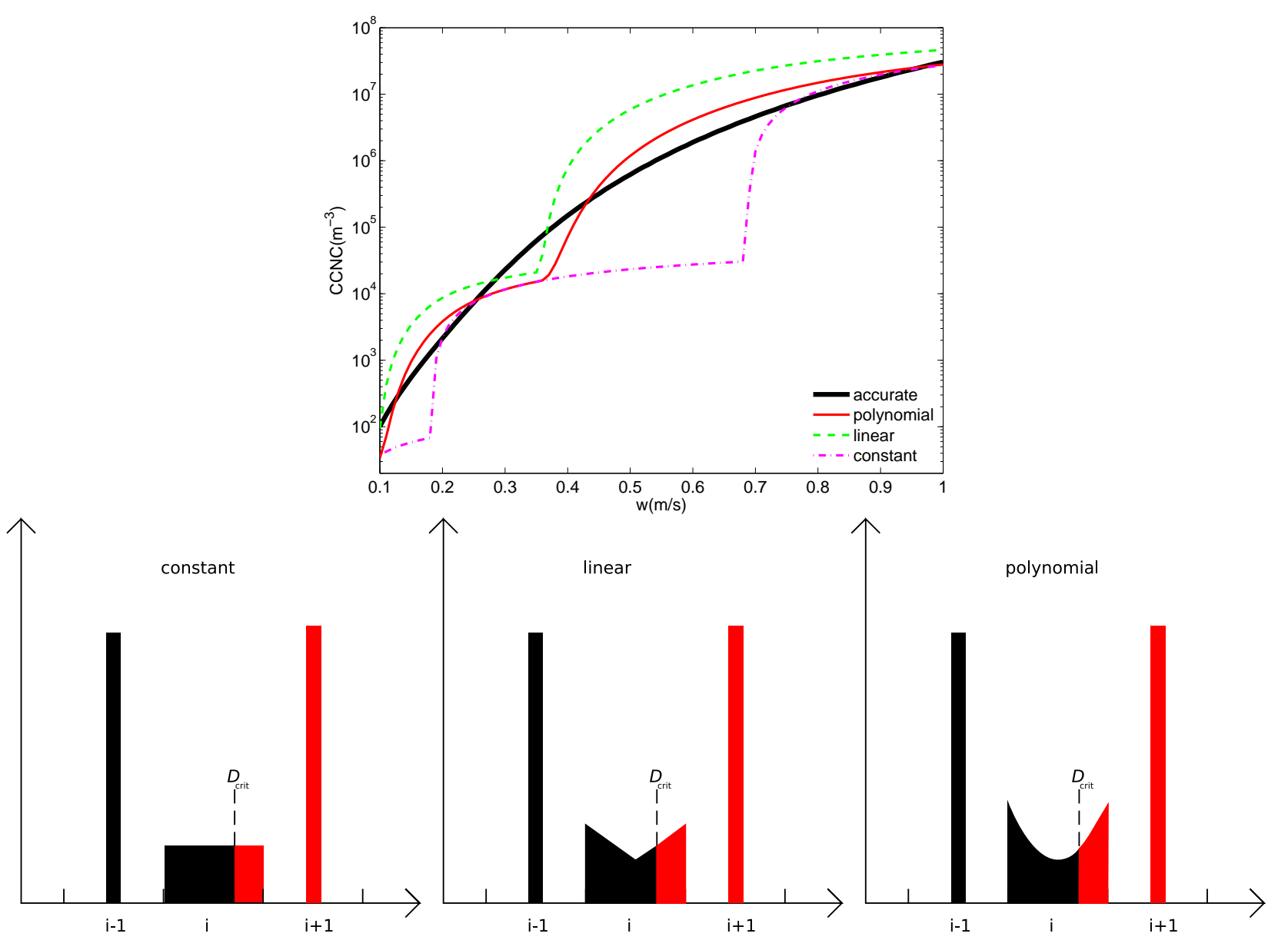

Fig. 2. Cloud droplet number concentration (CDNC) as a function of updraft velocity $w$ for four different approaches. Lower panels illustrates three different approaches for coarse grid setup.

ECHAM5 (Roeckner et al., 2003): $2400 \mathrm{~s}$ (T31L19), $1800 \mathrm{~s}$ (T42L19), $1200 \mathrm{~s}$ (T42L31 and T63L19), $900 \mathrm{~s}$ (T84L19), $720 \mathrm{~s}$ (T63L31 and T106L19), $480 \mathrm{~s}$ (T85L31), and $360 \mathrm{~s}$ (T106L31).

Size distributions used in the model verification for condensation and coagulation are given in Table 2. The given size distributions represent three different types of conditions: clear, hazy and urban conditions. In the evaluation, particles were assumed to be dry.

Figure 3 illustrates results for a case when only coagulation is taken into account. The dotted red curve represents the initial size distribution. The initial size distribution used here was the urban case given in Table 2. The solid red line is the size distribution after $12 \mathrm{~h}$ calculated using COAGUL. The dashed curve is calculated using a modal approach used in Models-3. The blue solid curve is calculated using SALSA using a $900 \mathrm{~s}$ time step and the blue dashed line is calculated using SALSA using a $2400 \mathrm{~s}$ time step. For time steps shorter than $900 \mathrm{~s}$ the final size distribution was approximately the same.
Figure 3 shows that when using the sectional approach, the shape of the accurate size distribution is reproduced clearly better than when using modal approach. Using a $900 \mathrm{~s}$ time step, the final total number concentration calculated using SALSA is approximately $5.5 \%$ smaller than the total number concentration calculated using COAGUL. Also, it can be seen from Fig 3 that for the longest time step of $2400 \mathrm{~s}$, the shape of the final size distribution is well reproduced.

Figure 4 shows results for simulations where condensation was the only microphysical process taken into account. The dotted red curve represents the initial volume size distribution, and the red solid line the final volume size distribution given by CONDEFF. The figure also shows results for the final size distribution calculated using different aerosol models. Lines with markers represent results from sectional aerosol models, and the dashed green curve shows results from Models-3 using modal approach. The solid blue curve is the final size distribution calculated using SALSA. For SALSA, the final size distribution was practically identical for all time steps used. 


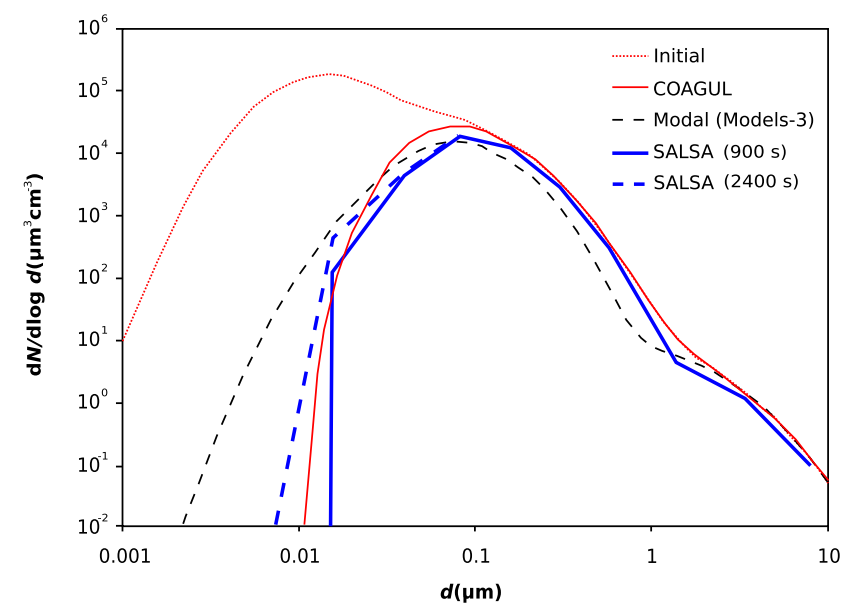

Fig. 3. Initial and final size distributions coagulation simulation. The dotted red curve is the initial size distribution. The red curve is the final size distribution using an explicit coagulation model COAGUL. The black dashed curve represents the final size distribution using a modal aerosol model and the thick blue line is the final size distribution calculated using SALSA. Results for COAGUL and modal aerosol model were adapted from Zhang et al. (1999)

Figure 4 illustrates that SALSA reproduces the shape of the accurate result of CONDEFF. The total volume concentration calculated using SALSA was approximately $1.4 \%$ smaller than the total volume concentration calculated using CONDEFF.

\subsection{Hygroscopic growth of the particles}

The ability of SALSA to describe the effect of composition on the wet aerosol size distribution was tested comparing SALSA against EQUISOLV II (Jacobson, 1999) which is an explicit thermodynamical equilibrium model calculating the thermodynamical equilibrium between gases, liquids, ions and solids. The compositions used in the subranges are shown in Table 3

Figure 5 shows the equilibrium sizes for particles in different size bins as a function of the water saturation ratio $S$. In the figure, subranges are denoted as 1, 2a, 2b, and 3a together with the index of the size bin beside the axes. The blue lines are the results from SALSA and the red lines are the results from EQUISOLV II.

The largest differences between SALSA and EQUISOLV II appear in the smallest subrange 1, and the smallest bins in subrange $2 \mathrm{a}$ at high water saturation ratios. This is probably due to different treatment of organics between the two models. EQUISOLV II also calculates explicitly the dissociation of sulfate into $\mathrm{HSO}_{4}^{-}$and $\mathrm{SO}_{4}^{2-}$. The smallest droplets are more highly concentrated and more sensitive to changes in the Kelvin effect, thus leading to large differences in the equilibrium droplet size.

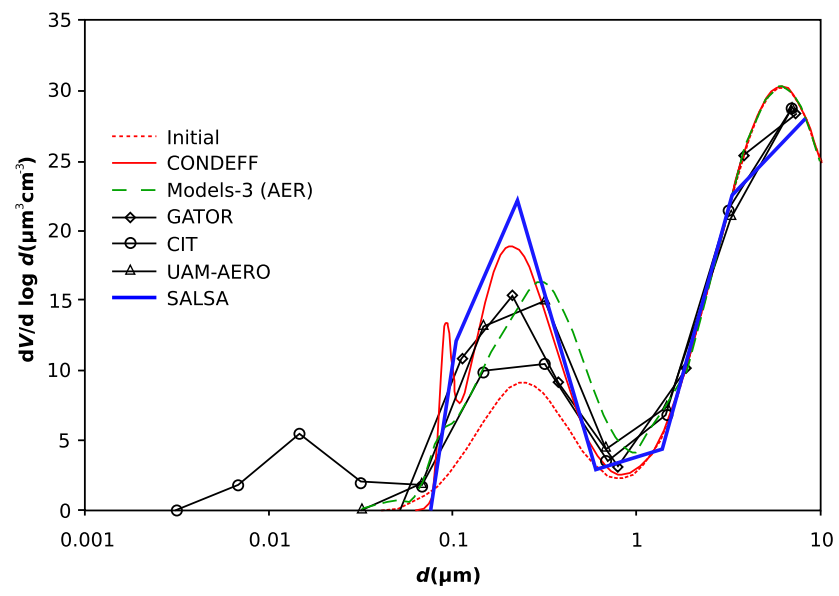

Fig. 4. Initial and final particle number concentration, for $12 \mathrm{~h}$ simulations for urban conditions. The dotted red curve is the initial size distribution and the solid red curve is the final size distribution from CONDEFF. The dashed green curve is the final size distribution calculated using a modal model, the black curves accompanied with markers are the final size distribution calculated using different sectional aerosol models, and the thick blue curve is the final size distribution calculated using SALSA. Results for models in comparison were adapted from Zhang et al. (1999)

Table 3. Chemical composition in subranges used in equilibrium size calculations.

\begin{tabular}{lllll}
\hline subrange & $\left(\mathrm{NH}_{4}\right)_{2} \mathrm{SO}_{4}$ & $\mathrm{OC}$ & $\mathrm{BC}$ & Sea salt \\
\hline 1 & 0.2 & 0.8 & & \\
$2 \mathrm{a}$ & 0.6 & 0.2 & 0.1 & 0.1 \\
$2 \mathrm{~b}$ & $5 \times 10^{-3}$ & 0.01 & 0.985 & \\
$3 \mathrm{a}$ & & & & 1 \\
\hline
\end{tabular}

\subsection{Insoluble vs. soluble size bins}

A large fraction of soot particles and practically all dust particles are almost insoluble in water when emitted to the atmosphere. Ageing of these particles in the atmosphere enhances their water uptake (e.g. Moteki et al., 2004; Riemer et al., 2004; Zuberi et al., 2005) and alters their light scattering and absorption properties (e.g. Jacobson, 2000; Sokolik et al., 2001; Schnaiter et al., 2005). In real atmosphere, processes modifying the hygroscopic and radiative properties of soot and dust particles are complicated and not yet properly understood (e.g. Schwarz et al., 2008).

While there are several ways how particles of different atmospheric "age" could be classified, practically all largescale models make this classification based on particle hygroscopic properties. For computational reasons, models are usually able to deal with only two particle types: "insoluble" particles which do not interact with clouds, and "soluble" particles which may contribute to cloud droplet populations 


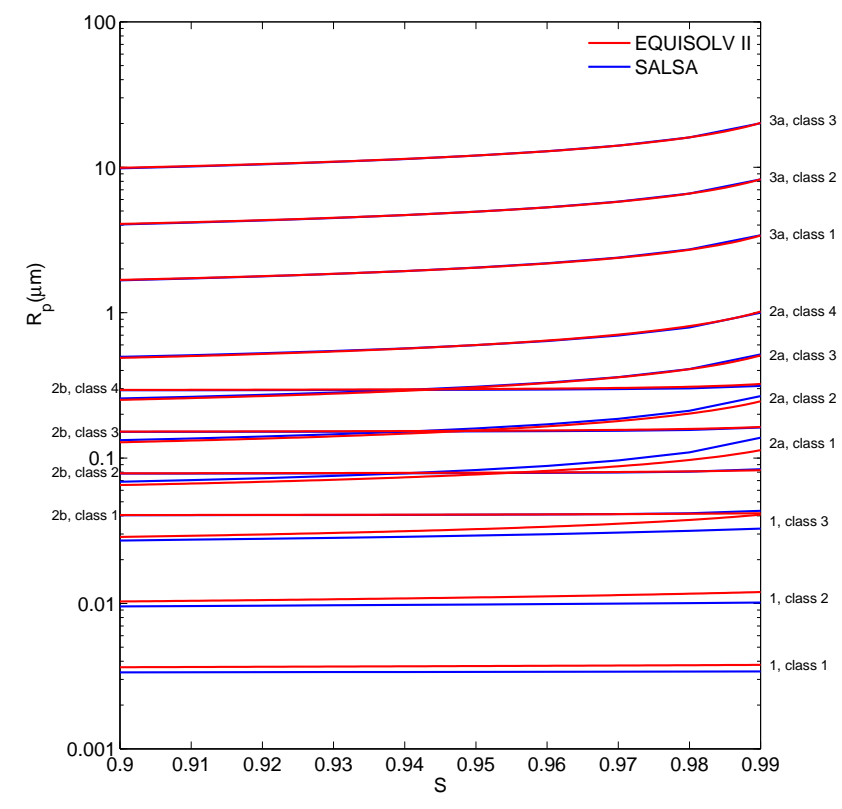

Fig. 5. Wet diameter of different size bins in subranges 1, 2a, and 3a as a function of water saturation ratio calculated using EQUISOLV II (red curves) and SALSA (blue curves).

and which are affected by wet deposition. The conversion of originally insoluble soot and dust particles to soluble ones is treated explicitly in only few of the current large-scale models (e.g. Croft et al., 2005; Stier et al., 2007). A crucial question in this regard is the proper timing of the insoluble-tosoluble transition in the model. If aged particles are moved too "early" from insoluble size bins to the corresponding soluble size bins, the hygroscopic properties of already soluble particles would be reduced too much. Likewise, too "late" transfer would cause underestimation of the number concentration of soluble particles prior to the transfer. In both cases, incorrect number of cloud droplets during the cloud formation would be predicted.

Testing how well a model performs in treating the insoluble-to-soluble transition is notoriously difficult. Ideally, such a test should be made in a three-dimensional framework with multiple sources of particles of different solubility and using a model that has a large number of size bins with multiple solubility classes in each size bin. Here we take a simpler approach by testing how sensitive the predicted cloud droplet number concentrations are to the transfer of particles from insoluble to soluble size bins.

To start with, we made a large number of simulations using the detailed cloud model with 300 size bins mentioned in Sect. 2.6. In these simulations, we varied the air updraft velocity (range $0.1-1 \mathrm{~m} / \mathrm{s}$ ), particle number size distribution (marine, rural and urban distributions in Table 1), soluble volume fraction of "insoluble" particles (range 0.0001-0.1 for the volume fraction of sulfate in subrange $2 b$ ), and sol-

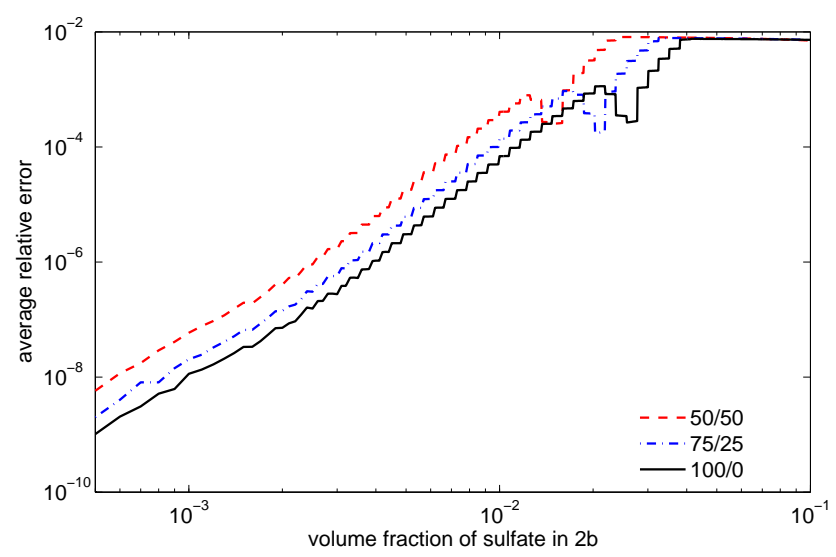

Fig. 6. Average relative difference in the number of activating cloud droplets when particles are moved from insoluble size bins to soluble size bins compared to a case where particles remained in their original size bins. Relative error is given as a function of volume fraction of sulfate for different volume ratios of sulfate and black carbon in subrange $2 \mathrm{a}$. Calculations were done using 300 size bins in size space.

uble volume fraction of "soluble" particles (volume ratios of 50/50, 75/50 and 100/0 between sulfate and black carbon in subrange 2a). An equal number of insoluble and soluble particles were assumed. Each simulation was made in two different ways: with or without moving particles from the insoluble size bins into the corresponding soluble size bins.

Figure 6 illustrates the relative differences in calculated cloud droplet number concentrations between the cases where all insoluble particles were moved into soluble size bins and cases where they were not. The urban particle number size distribution was chosen because it led to the largest differences. We may see that the relative differences increased with increasing soluble fraction of "insoluble" particles but were quite low $(<0.01)$ over the whole variable range considered. This suggests that the cloud droplet nucleating properties of externally-mixed particle populations are not very sensitive to the exact treatment (timing) of the insoluble-to-soluble particle transfer, provided that this transfer is made before "insoluble" particles become very hygroscopic.

Next, we performed the same set of simulations with the difference that the model runs with insoluble-to-soluble transfer and subsequent cloud droplet activation were made using SALSA. The results are shown in Fig. 7. We may see that due to the course resolution (10 size bins) of SALSA compared with the cloud model with 300 size bins, the relative differences in predicted cloud droplet number concentrations are clearly larger than those in Figure 6. However, the differences can still be considered fairly low considering that this is kind of a "worse case scenario". Under conditions more typical for the global atmosphere, the number concentration of insoluble particles is expected to much lower than 


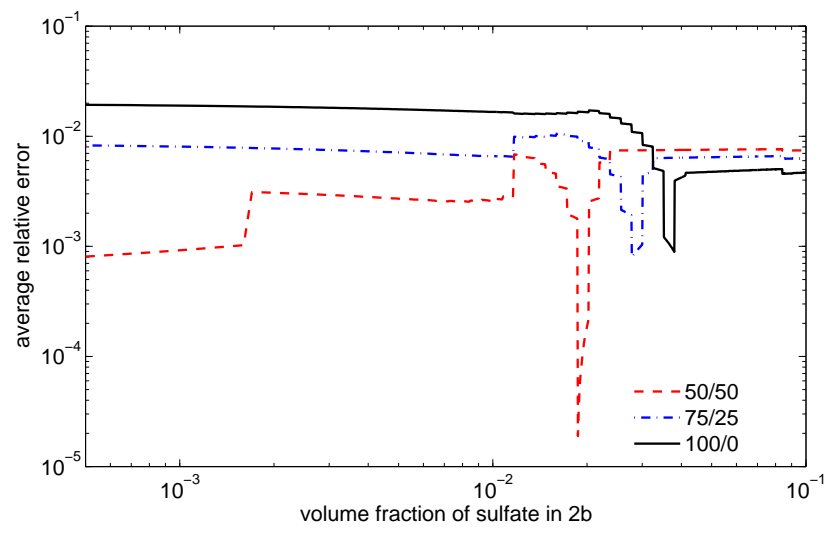

Fig. 7. Average relative error in the number of activating cloud droplets when particles are moved from insoluble size bins to soluble size bins using 10 size bins in size space, compared to a case calculated using model setup of 300 size bins in size space where particles remained in their original size bins. Relative error is given as a function of vertical velocity for different volume ratios of sulfate and black carbon.

that of soluble particles. Considering the large overall uncertainties in representing the aerosol mixing state in current large-scale models, we conclude that our method of moving particles from insoluble to soluble size bins works well enough not too cause any serious additional errors in simulations.

\subsection{All microphysical processes combined}

Finally, the model was evaluated simulating a nucleation event typical in a highly polluted area of Po Valley, Italy. The ambient size distribution and the values $280.6 \mathrm{~K}$ for temperature and $83 \%$ for relative humidity were taken from measurements (Hamed et al., 2007). The gas phase concentration for sulfuric acid was derived from measured $\mathrm{OH}$ concentrations and can be seen in Fig. 8a. Since there was no measurement data available for organic gases, the gas phase concentrations were assumed to be equal to those of sulfuric acid. The event was compared against a high resolution model simulation using SALSA with 300 size bins in size space. The initial conditions were approximated using measured conditions at 8 am before the observed nucleation event. Initial ambient size distribution was chosen as tri-modal with geometric median diameters of $5 \mathrm{~nm}, 20 \mathrm{~nm}$, and $100 \mathrm{~nm}$, number concentrations of $4000 \mathrm{~cm}^{-3}, 8000 \mathrm{~cm}^{-3}$, and $2000 \mathrm{~cm}^{-3}$ for each mode, respectively. The geometric standard deviation for each mode was set to be 1.5 .

Figure $8 \mathrm{~b}$ illustrates the contour plot of the particle number concentrations during a simulated nucleation event calculated using 300 size bins. In Fig. 8c, the same event was simulated using the default bin setup of 3 size bins in subrange 1, 4 size bins in subrange 2 , and 3 size bins in sub- range 3. In Fig. 8d, the total number concentrations for these two simulations are presented. The same simulation was repeated using different default time steps of ECHAM5 (see Sect. 3.1), but the results were practically the same for all time steps lengths.

From Fig. 8 it can be seen that, overall, the default model setup reproduces the number concentrations well compared to the high resolution model setup. At the beginning of the simulation, the total number concentrations are underestimated, and also after the actual nucleation burst the processing of the aerosol size distribution by condensation and coagulation shows surprisingly good agreement when the high resolution and coarse simulations are compared.

\subsection{Technical details}

The model is written in Fortran 90 in modular form to make it easy to include it in existing large-scale models. The selection of number and location of size sections, processes active on different sections as well as many key parameters are easily changeable from model to another.

SALSA was tested in a general circulation model ECHAM5-HAM (Roeckner et al., 2003; Stier et al., 2005) where it was implemented as an optional microphysical module. Currently ECHAM5 includes a modal aerosol module M7 (Vignati et al., 2004). To include a sectional module in ECHAM5-HAM also required modifying aerosol processes of the aerosol module HAM to apply sectional scheme. Preliminary simulations using SALSA coupled with ECHAM5HAM show less than $30 \%$ increase in calculation time for one month simulations replacing the modal aerosol model M7. We can therefore conclude that the model SALSA is computationally efficient enough to be used in large scale circulation model. A more detailed performance evaluation of SALSA within ECHAM will be reported in the near future.

\section{Discussion}

We have developed an aerosol dynamics model package suitable for large scale models. Sectional approach provides a much more flexible way to simulate the aerosol size distribution, as it does not assume any explicit shape of the population. Our approach, which tries to only simulate the climatologically important aerosol properties without oversimplifying the processes, is in our opinion a good way to prepare a complete view of aerosol dynamic effects to the climate. However, realities of model development inherently forces the developers to make simplifying assumptions or model design choices.

One such issue is the choice of number of sections. We have selected the number of sections and their properties in the default case to best produce in our opinion the most important aerosol process - aerosol-cloud interactions - as well as possible given the calculation resource restrains. A more 

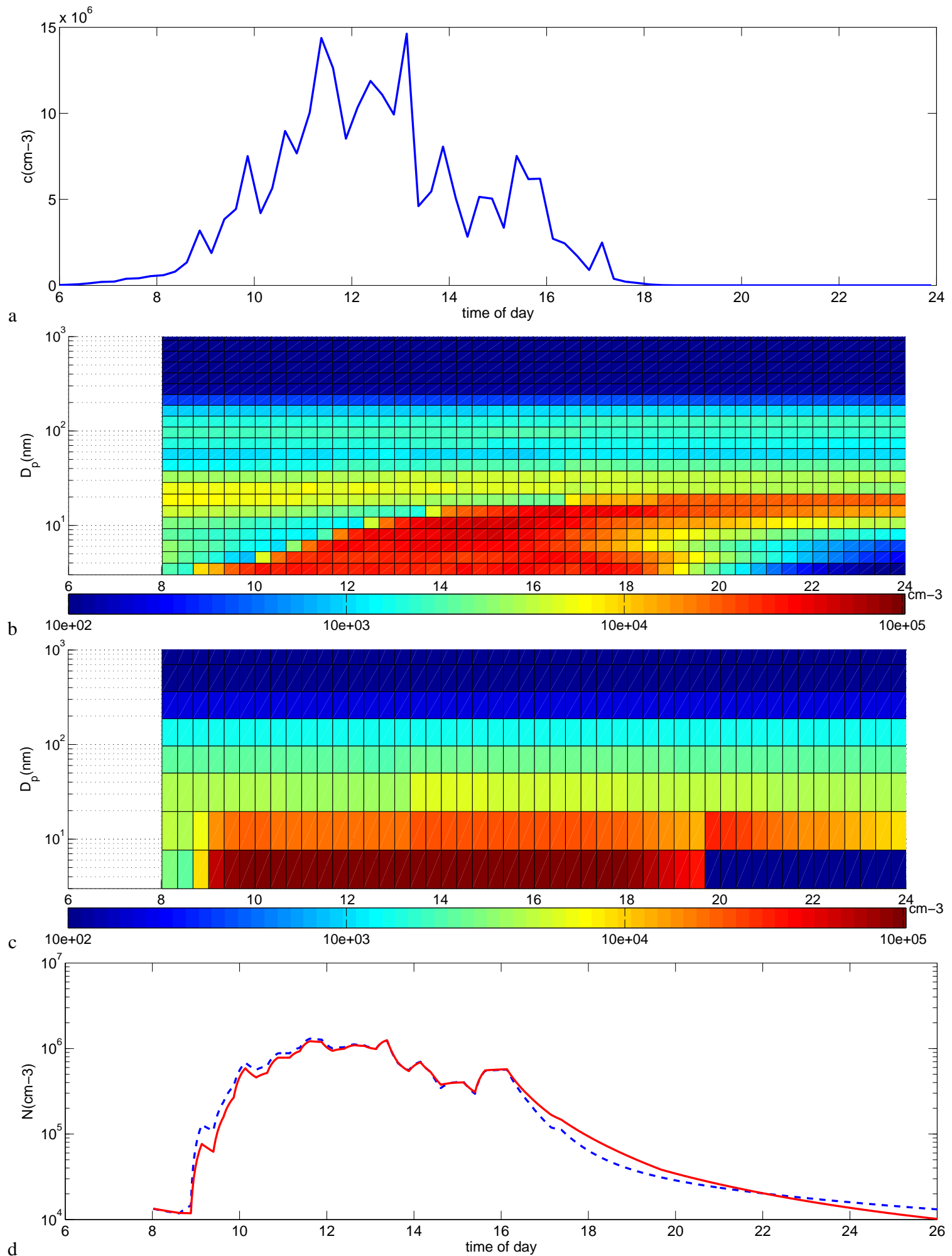

Fig. 8. a) Gas phase concentration of sulfuric acid and condensable organic vapor as a function of time. b) Number concentrations of particles as a function of time and diameter calculated using 300 size bins in size space. c) Number concentrations of particles as a function of time and diameter calculated using 3, 4, and 3 size bins in subranges 1, 2, and 3, respectively. d) Total number concentrations for the high resolution (blue dashed line) and coarse model setup (red solid line). 
detailed size distribution handling is of course possible in the model framework, but as the model evaluation in this paper shows, the current model does a very good job effort in capturing the processes. An another question altogether is can the number of sections be reduced. The advantages of such approach are clear, as the number of sections is the most critical issue for computational efficiency of the model. Based on the work here, we can predict that at least a radical reduction of number of sections will lead to a significant drop in model performance. However, such changes should be throughly tested for microphysical accuracy.

The default model configuration takes into account both particle size and composition in cloud activation processes. The particle size resolution is increased in the sizes where the cloud activation will most likely to be sensitive to the particle diameter. Additionally, the particle activation is also handled as a sub-section parameterization. For particle composition effect, we have taken into account external mixing of soluble and insoluble particles in the most sensitive aerosol fraction. It is an ongoing debate in the cloud activation literature, which of the effects are more important (Dusek et al., 2006; McFiggans et al., 2006), but in our opinion relevant microphysical handling of both is necessary in the default model configuration.

In the default configuration, the role of the model organic copound is just to act as a surrogate for most organic species. This is also obvious on the quite simplistic way of calculating the binary molality of the model organic compound. Addition of more detailed organic package is beyond the intended scope of this work, but the model framework is well suited for such more detailed studies of organic aerosol effects.

The default model framework does assume that the parent model can provide many necessary boundary conditions and concentrations for SALSA model. The choice of input parameters is selected to best fit as an aerosol model for ECHAM5-HAM climate model (Roeckner et al., 2003; Stier et al., 2005). Especially some aerosol related input functions, such as emission modelling is not included and should be separately investigated for each model to best fit the intended resolution and model configuration.

\section{Conclusions}

A new sectional aerosol microphysical model designed for large scale modelling purposes has been developed and tested against existing aerosol models.

The aerosol size distribution in the model is divided into three subranges according to dominant processes and chemical components in different sized particles. Only the relevant processes and components are calculated for each subrange. The densest size section spacing is reserved for particles from $50 \mathrm{~nm}$ to $730 \mathrm{~nm}$ in order to capture the changes in this size range that is the most important in anthropogenic climate change.
The model uses the moving-center scheme by Jacobson (2005) to describe the aerosol size distribution of particle smaller than $730 \mathrm{~nm}$, i.e. below this threshold size average number as well mass concentrations of chemical components in each section are carried as tracers. As particle growth for particles in the coarse mode is very slow, particles larger than $730 \mathrm{~nm}$ are represented with fixed size sections.

Comparison against explicit solutions of coagulation and condensation equations show that the model captures the changes in the aerosol size distribution well despite its relatively coarse size resolution of 10 sections from $3 \mathrm{~nm}-10$ $\mu \mathrm{m}$.

It is particularly noteworthy that this fairly coarse sectional representation tracks the evolution of the particle size distribution much more accurately in the test cases than the multimodal representation it was compared against. Especially, the concentration of accumulation mode particles, the most important size range concerning direct and indirect climate effects of aerosol particles, was reproduced much better with the new model owing largely to the size distribution description in subrange 2. The denser size sectioning in this subrange led to a more accurate description of cloud droplet activation and sulphate production in cloud droplets.

Acknowledgements. This work has been partly funded by European Commission project EUCAARI ( $\mathrm{N}_{o} 036833-2$ (EUCAARI)).

Edited by: A. Wiedensohler

\section{References}

Abdul-Razzak, H. and Ghan, S. J.: A parameterization of aerosol activation 3. Sectional representation, J. Geophys. Res., 107, doi:10.1029/2001JD000483, 2002.

Abdul-Razzak, H., Ghan, S. J., and Rivera-Carpio, C.: A parameterization of aerosol activation 1. Single aerosol type, J. Geophys. Res., 103, 6123-6131, 1998.

Ackermann, I. J., Hass, H., Memmesheimer, M., E. A., Binkowski, F. S., and Shankar, U.: Modal Aerosol Dynamics Model for Europe: Development and First Applications, Atmos. Environ., 32, 2981-2999, 1998.

Adams, P. J. and Seinfeld, J. H.: Predicting global aerosol size distributions in general circulation models, J. Geophys. Res.Atmos., 107, 4-1, doi:10.1029/2001JD001010, 2002.

Alfaro, S. C. and Gomes, L.: Modeling mineral aerosol production by wind erosion: Emission intensities and aerosol size distributions in source areas, J. Geophys. Res., 106, 18 075-18 084, 2001.

Binkowski, F. S. and Roselle, S. J.: Models-3 Community Multiscale Air Quality (CMAQ) model aerosol component 1. Model description., J. Geophys. Res., 108, 4183, doi:10.1029/2001JD001409, 2003.

Binkowski, F. S. and Shankar, U.: The Regional Particulate Matter Model. 1. Model Description and Preliminary results, J. Geophys. Res., 100, 26 191-26209, 1995. 
Bohren, C. F. and Huffman, D. R.: Absorption and scattering of light by small particles, John Wiley \& Sons inc., 1983.

Boucher, O. and Anderson, T. L.: General circulation model assessment of the sensitivity of direct climate forcing by anthropogenic sulfate aerosols to aerosol size and chemistry, J. Geophys. Res., 100, 26 117-26 134, 1995.

Cantrell, C. and Heymsfield, A.: Production of ice in tropospheric clouds: A review, Bull. Amer. Meteor. Soc., 66, 795-807, 2005.

Chang, M.-C., Chow, J. C., Watson, J. G., Hopke, P. K., Yi, S.M., and England, G. C.: Measurement of ultrafine particle size distributions from coal-, oil-, and gas-fires stationary combustion sources, J. Air Waste Manage. Assoc., 54, 1494-1505, 2004.

Chen, Y. and Penner, J. E.: Uncertainty analysis for estimates of the first indirect aerosol effect, Atmos. Chem. Phys. Discuss., 5, 4507-4543, 2005,

http://www.atmos-chem-phys-discuss.net/5/4507/2005/.

Croft, B., Lohmann, U., and von Salzen, K.: Black carbon ageing in the Canadian Centre for Climate modelling and analysis atmospheric general circulation model, Atmos. Chem. Phys., 5, 1931-1949, 2005,

http://www.atmos-chem-phys.net/5/1931/2005/.

Dusek, U., Frank, G. P., Hildebrandt, L., Curtius, J., Schneider, J., Walter, S., Chand, D., Drewnick, F., Hings, S., Jung, D., Borrmann, S., and Andreae, M. O.: Size Matters More Than Chemistry for Cloud-Nucleating Ability of Aerosol Particles, Science, 312, 1375-1378, doi:10.1126/science.1125261, http:// www.sciencemag.org/cgi/content/abstract/312/5778/1375, 2006.

Ferron, G. A., Karg, E., Busch, B., and Heyder, J.: Ambient particles at an urban, semi-urban and rural site in Central Europe: hygroscopic properties, Atmos. Environ., 39, 343-352, 2005.

Ghan, S., Laulainen, N., Easter, R., Wagener, R., Nemesure, S., Chapman, E., Zhang, Y., and Leung, R.: Evaluation of aerosol direct radiative forcing in MIRAGE, J. Geophys. Res., 106, 52955316, 2001.

Grini, A. and Zender, C. S.: Roles of saltation, sandblasting, and wind speed variability on mineral dust aerosol size distribution during the Puerto Rican Dust Experiment (PRIDE), J. Geophys. Res., 109, doi:10.1029/2003JD004233, 2004.

Hamed, A., Joutsensaari, J., Mikkonen, S., Sogacheva, L., Maso, M. D., Kulmala, M., Cavalli, F., Fuzzi, S., Facchini, M. C., Decesari, S., Mircea, M., Lehtinen, K. E. J., and Laaksonen, A.: Nucleation and growth of new particles in Po Valley, Italy, Atmos. Chem. Phys., 7, 355-376, 2007,

http://www.atmos-chem-phys.net/7/355/2007/.

Henning, S., Weingartner, E., Schmidt, S., Wendisch, M., Gäggeler, H. W., and Baltensberger, U.: Size-dependent aerosol activation at the high-alpine site Jungfraujoch (3580 $\mathrm{m}$ a.s.1.), Tellus, 54B, 82-95, 2002.

Iinuma, Y., Brüggemann, E., Gnauk, T., Müller, K., Andreae, M. O., Helas, G., Parmar, R., and Herrmann, H.: Source characterization of biomass burning particles: The combustion of selected European conifers, African hardwood, savanna grass, and German and Indonesian peat, J. Geophys. Res., 112, D08209, doi:10.1029/2006JD007120, 2007.

Jacobson, M. Z.: Developing, coupling and applying a gas, aerosol, transport and radiation model to study urban and regional air pollution, Ph.D. thesis, Dept. of Atmospheric Sciences, University of California, Los Angeles, 1994.

Jacobson, M. Z.: Numerical techniques to solve condensational and dissolutional growth equations when growth is coupled to reversible reactions, Aerosol Sci. Technol., 27, 491-498, 1997.

Jacobson, M. Z.: Studying the effects of calcium and magnesium on size-distributed nitrate and ammonium with EQUISOLV II, Atmos. Environ., 33, 3635-3649, 1999.

Jacobson, M. Z.: A Physically-Based Treatment of Elemental Carbon Optics: Implications for Global Direct Forcing of Aerosols, Geophys. Res. Lett., 27, 217-220, 2000.

Jacobson, M. Z.: GATOR-GCMM: A global through urban scale air pollution and weather forecast model. 1. Model design and treatment of subgrid soil, vegetation, roads, rooftops, water, sea ice, and snow., J. Geophys. Res., 106, 5385-5402, 2001.

Jacobson, M. Z.: Analysis of aerosol interactions with numerical techniques for solving coagulation, nucleation, condensation, dissolution, and reversible chemistry among multiple size distributions, J. Geophys. Res., 107, 4366, doi:10.1029/2001JC002044, 2002.

Jacobson, M. Z.: Fundamentals of Atmospheric Modeling, Second Edition, Cambridge University Press, New York, 2005.

Jaenicke, R.: Aerosol-cloud-climate interactions, chap. Tropospheric aerosols, pp. 1-31, Academic Press, San Diego, 1993.

Jaffrezo, J. L., Aymoz, G., and Cozic, J.: Size distribution of EC and $\mathrm{OC}$ in the aerosol of Alpine valleys during summer and winter, Atmos. Chem. Phys., 5, 2915-2925, 2005, http://www.atmos-chem-phys.net/5/2915/2005/.

Kerminen, V.-M. and Kulmala, M.: Analytical formulae connecting the "real" and the "apparent" nucleation rate and the nuclei number concentration for atmospheric nucleation events, J. Aerosol Science, 33, 609-622, 2002.

Komppula, M., Lihavainen, H., Kerminen, V. M., Kulmala, M., and Viisanen, Y.: Measurements of cloud droplet activation of aerosol particles at a clean subarctic background site, J. Geophys. Res., 110, D06204, doi:10.1029/2004JD00520, 2005.

Korhonen, H., Kerminen, V.-M., Lehtinen, K. E. J., and Kulmala, M.: CCN activation and cloud processing in sectional aerosol models with low size resolution, Atmos. Chem. Phys., 5, 25612570, 2005, http://www.atmos-chem-phys.net/5/2561/2005/.

Kulmala, M., Vehkamaki, H., Petaja, T., Maso, M. D., Lauri, A., Kerminen, V. M., Birmili, W., and McMurry, P. H.: Formation and growth rates of ultrafine atmospheric particles: a review of observations, J. Aerosol Science, 35, 143-176, 2004.

Kulmala, M., Lehtinen, K. E. J., and Laaksonen, A.: Cluster activation theory as an explanation of the linear dependence between formation rate of $3 \mathrm{~nm}$ particles and sulphuric acid concentration, Atmos. Chem. Phys., 6, 787-793, 2006, http://www.atmos-chem-phys.net/6/787/2006/.

Lehtinen, K. E. J., Rannik, U., Kulmala, M., and Hari, P.: Nucleation rate and vapour concentration estimations using a least squares aerosol dynamics method, J. Geophys. Res., 109, doi:10.1029/2004JD004893, 2004.

Liao, H. and Seinfeld, J.: Global impacts of gas-phase chemistryaerosol interactions on direct radiative forcing by anthropogenic aerosols and ozone, J. Geophys. Res., 110, D18208, doi:10.1029/ 2005JD005907, 2005.

Liu, H. Q., Pinker, R. T., and Holben, B. N.: A global view of aerosols from merged transport models, satellite, and ground observations, J. Geophys. Res., 110,D10S15, doi:10.1029/2004JD004695, 2005. 
McFiggans, G., Artaxo, P., Baltensperger, U., Coe, H., Facchini, M. C., Feingold, G., Fuzzi, S., Gysel, M., Laaksonen, A., Lohmann, U., Mentel, T. F., Murphy, D. M., O’Dowd, C. D., Snider, J. R., and Weingartner, E.: The effect of physical and chemical aerosol properties on warm cloud droplet activation, Atmos. Chem. Phys., 6, 2593-2649, 2006,

http://www.atmos-chem-phys.net/6/2593/2006/.

McGraw, R.: Description of aerosol dynamics by the quadrature method of moments, Aerosol Sci. Tech., 27, 255-265, 1997.

Mertes, S., Lehman, K., Nowak, A., Massling, A., and Wiedensohler, A. A.: Link between aerosol hygroscopic growth and droplet activation observed for hill-capped clouds at connected flow conditions during FEBUKO, Atmos. Environ., 39, 42474256, 2005.

Moteki, N., Kondo, Y., Miyazaki, Y., Takegawa, N., Komazaki, Y., Kurata, G., Shirai, T., Blake, D. R., R., Miyakawa, T., and Koike, M.: Evolution of mixing state of black carbon particles: Aircraft measurements over the western Pacific in March, Geophys. Res. Lett., 34, L11803, doi:10.1029/2006GL028943, 2004.

Myhre, G., Stordahl, F., Berglen, T., Sundet, J., and Isaksen, I.: Uncertainties in the radiative forcing due to sulphate aerosols, J. Atmos. Sci., 61, 485-498, 2004.

Napari, I., Noppel, M., Vehkamaki, H., and Kulmala, M.: An improved model for ternary nucleation of sulfuric acid-ammoniawater, J. Chem. Phys., 116, 4221-4227, http://link.aip.org/link/ ?JCP/116/4221/1, 2002a.

Napari, I., Noppel, M., Vehkamäki, H., and Kulmala, M.: Parameterization of ternary nucleation rates for $\mathrm{H}_{2} \mathrm{SO}_{4}$ - $\mathrm{NH}_{3}-\mathrm{H}_{2} \mathrm{O}$ vapors., J. Geophys. Res., 107, 4381, doi:10.1029/2002JD002132, 2002b.

Reddy, M. S., Boucher, O., Bellouin, N., Schulz, M., Balkanski, Y., Dufresne, J. L., and Pham, M.: Estimates of global multicomponent aerosol optical depth and direct radiative perturbation in the Laboratoire de Meteorologie Dynamique general circulation model, J. Geophys. Res., 110, D10S16, doi:10.1029/2004JD004757, 2005.

Riemer, N., Vogel, H., and Vogel, B.: Soot aging time scales in polluted regions during day and night, Atmos. Chem. Phys., 4, 1885-1893, 2004,

http://www.atmos-chem-phys.net/4/1885/2004/.

Riipinen, I., Sihto, S.-L., Kulmala, M., Arnold, F., Maso, M. D., Birmili, W., Saarnio, K., Teinilä, K., Kerminen, V.-M., Laaksonen, A., and Lehtinen, K. E. J.: Connections between atmospheric sulphuric acid and new particle formation during QUEST III, IV campaigns in Heidelberg and Hyytiälä, Atmos. Chem. Phys., 7, 1899-1914, 2007,

http://www.atmos-chem-phys.net/7/1899/2007/.

Rodriguez, M. and Dabdub, D. J.: IMAGES-SCAPE2: A modeling study of size and chemically resolved aerosol thermodynamics in a global chemical transport model, J. Geophys. Res., 109,D22S04, doi:10.1029/2003JD003639, 2004.

Roeckner, E., Bäuml, G., Bonaventura, L., Brokopf, R., Esch, M., Giorgetta, M., Hagemann, S., Kirchner, I., Kornblueh, L., Manzini, E., Rhodin, A., Schlese, U., Schulzweida, U., and Tompkins, A.: The atmospheric general circulation model ECHAM5. PART I: Model description, MPI-Report, 349, 127 pp., 2003.

Sakurai, H., Fink, M. A., McMurry, P. H., Mauldin, L., Moore, K. F., Smith, J. N., and Eisele, F. L. F. L.: Hygroscopicity and volatility of 4-10 $\mathrm{nm}$ particles during summertime atmospheric nucleation events in urban Atlanta, J. Geophys. Res., 110, D22S04, doi:10.1029/2005JD005918, 2005.

Schnaiter, M., Linke, C., Möhler, O., Naumann, K.-H., Saathoff, H., Wagner, R., Schurath, U., and Wehner, B.: Absorption amplification of black carbon internally mixed with secondary organic aerosol, J. Geophys. Res., 110, D19204, doi:10.1029/2005JD006046, 2005.

Schwarz, J. P., Spackman, J. R., Fahey, D. W., Gao, R. S., Lohmann, U., Stier, P., Watts, L. A., Thomson, D. S., Lack, D. A., Pfister, L., Mahoney, M. J., Baumgardner, D., Wilson, J. C., and Reeves, J. M.: Coatings and their enhancement of black carbon light absorption in the tropical atmosphere, J. Geophys. Res., 113, D03203, 2008.

Seinfeld, J. H. and Pandis, S. N.: Atmospheric Chemistry and Physics, John Wiley \& Sons inc., 1998.

Sihto, S.-L., Kulmala, M., Kerminen, V.-M., Maso, M. D., Petäjä, T., Riipinen, I., Korhonen, H., Arnold, F., Janson, R., Boy, M., Laaksonen, A., and Lehtinen, K. E. J.: Atmospheric sulphuric acid and aerosol formation: implications from atmospheric measurements for nucleation and early growth mechanisms, Atmos. Chem. Phys., 6, 4079-4091, 2006, http://www.atmos-chem-phys.net/6/4079/2006/.

Sokolik, I. N., Winker, D. M., Bergametti, G., Gillette, D. A., Carmichael, G., Kaufman, Y. J., Gomes, L., Schuetz, L., and Penner, J. E.: Introduction to special section: Outstanding problems in quantifying the radiative impacts of mineral dust, J. Geophys. Res., 106, 18015-18027, 2001.

Spracklen, D. V., Springle, K. S., Carslaw, K. S., Chipperfield, M. P., and Mann, G. W.: A global off-line model of size-resolved aerosol microphysics, Atmos. Chem. Phys., 5, 3233-3250, 2005, http://www.atmos-chem-phys.net/5/3233/2005/.

Spracklen, D. V., Carslaw, K. S., Kulmala, M., Kerminen, V. M., Mann, G. W., and Sihto, S. L.: The contribution of boundary layer nucleation events to total particle concentrations on regional and global scales, Atmos. Chem. Phys., 6, 5631-5648, 2006 , http://www.atmos-chem-phys.net/6/5631/2006/.

Stier, P., Feichter, J., Kinne, S., Kloster, S., Vignati, E., Wilson, J., Ganzeveld, L., Tegen, I., Werner, M., Balkanski, Y., Schulz, M., Boucher, O., Minikin, A., and Petzold, A.: The aerosolclimate model ECHAM5-HAM, Atmos. Chem. Phys., 5, 11251156, 2005, http://www.atmos-chem-phys.net/5/1125/2005/.

Stier, P., Seinfeld, J. H., Kinne, S., and Boucher, O.: Aerosol absorption and radiative forcing, Atmos. Chem. Phys., 7, 52375261, 2007, http://www.atmos-chem-phys.net/7/5237/2007/.

Stokes, R. H. and Robinson, R. A.: Interactions in aqueous nonelectrolyte solutions. I. Solute-solvent equilibria, J. Phys. Chem., 70, 2126-2130, 1996.

Tang, I. N.: Thermodynamic and optical properties of mixedsalt aerosols of atmospheric importance, J. Geophys. Res., 102, 1883-1893, 1997.

Vehkamäki, H., Kulmala, M., Napari, I., Lehtinen, K. E. J., Timmreck, C., Noppel, M., and Laaksonen, A.: An improved parameterization for sulfuric acid-water nucleation rates for tropospheric and stratospheric conditions, J. Geophys. Res., 107, 4622, doi:10.1029/2002JD002184, 2002. 
Vignati, E., Wilson, J., and Stier, P.: M7: An efficient size-resolved aerosol microphysics module for large-scale aerosol transport models, J. Geophys. Res., 109,D22202, doi:10.1029/2003JD004485, 2004.

Väkevä, M., Kulmala, M., Stratmann, F., and H-"ameri, K.: Field measurements of hygroscopic properties and state of mixing of nucleation mode particles, Atmos. Chem. Phys., 2, 55-66, 2002, http://www.atmos-chem-phys.net/2/55/2002/.

Wehner, B., Philippin, S., Wiedensohler, A., Scheer, V., and Vogt, R.: Variability of non-volatile fractions of atmospheric aerosol particles with traffic influence, Atmos. Environ., 38, 6081-6090, 2004.

Weisenstein, D. K., Penner, J. E., Herzog, M., and Liu, X.: Global 2-D intercomparison of sectional and modal aerosol modules, Atmos. Chem. Phys., 7, 2339-2355, 2007,

http://www.atmos-chem-phys.net/7/2339/2007/.
Wilson, J., Cuvelier, C., and Raes, F.: A modeling study of global mixed aerosol fields, J. Geophys. Res., 106, 34 081-34 108, 2001.

Zhang, Y., Seigneur, C., Seinfeld, J. H., Jacobson, M. Z., and Binkowski, F. S.: Simulation of Aerosol Dynamics: A Comparative Review of Algorithms Used in Air Quality Models, Aerosol Sci. Tech., 31, 487-514, 1999.

Zuberi, B., Johnson, K. S., Aleks, G. K., Molina, L. T., and Molina, M. J.: Hydrophilic properties of aged soot, Geophys. Res. Lett., 32, L01807, doi:10.1029/2004GL021496, 2005. 